\title{
JSST Editorial
}

\section{Michel A. Aegerter ${ }^{1} \cdot$ John Bartlett ${ }^{1}$}

Published online: 24 January 2022

(c) The Author(s), under exclusive licence to Springer Science+Business Media, LLC, part of Springer Nature 2022

In this issue, the JSST Editors are proud to present the first 13 invited papers to be published as part of the new JSST TOPICAL COLLECTIONS series. After many discussions with the Journal Editors and Editorial Board members in 2020, 13 initial themes were selected for the series, with leading sol-gel practitioners invited to contribute their work. In this issue, you will find papers accepted for inclusion in the first five themes:

- JSST History (one paper);

- Batteries via Solution Processing including non-oxidebased Sol-Gel Processes (four papers);

- Perspectives on Past Achievement and Future Opportunities in Sol-Gel (one paper);

- Women in Sol-Gel (five papers); and

- Focus on Techniques (two papers).

Michel A. Aegerter

michel.aegerter@bluewin.ch

1 Journal of Sol-Gel Science and Technology http://orcid.org/00000000-0000-0000
The submissions for nine other themes are also nearing completion. These include Sol-Gel Research in Japan; Nanohybrids and Nanocomposites; Applications close to Industry; Sol-Gel Research in China; Sol-Gel Research in Latin America; Non-oxide Based Sol-Gel Processes; SolGel Science and Technology in Art and Heritage Conservation; and ISGS e-Seminar. These will appear soon in the journal.

Thanks to the success of this idea, six other series are still under preparation.

We hope that all of our readers will enjoy these new JSST Topical Collections and your comments and suggestions are of course welcome. 